\title{
The impact of delaying acute kidney stone surgery on outcomes
}

Anis Assad ${ }^{1}$; David-Dan Nguyen ${ }^{2}$; Iman Sadri ${ }^{2}$; Naeem Bhojani ${ }^{1}$

${ }^{1}$ Department of Urology, University of Montreal, Montreal, QC, Canada; ${ }^{2}$ Faculty of Medicine, McGill

University, Montreal, QC, Canada

Cite as: Assad A, Nguyen D-D, Bhojani N. The impact of delaying acute kidney stone surgery on outcomes. Can Urol Assoc J 2021 January 4; Epub ahead of print. http://dx.doi.org/10.5489/cuaj.6877

Published online January 4, 2021

$* * *$

\section{Introduction}

Kidney stone disease is very common and its incidence is increasing. ${ }^{1}$ The main management option for kidney stones is surgery. However, with the outbreak of the coronavirus disease (COVID-19), elective surgical procedures, such as those for kidney stones, have been put on hold due to resource allocation and competing risk considerations.

The initial management of acute renal colic depends on the severity of the clinical presentation. A conservative approach is recommended in selected patients knowing that up to $95 \%$ of ureteric stones $<5 \mathrm{~mm}$ can pass spontaneously. ${ }^{2}$ By contrast, urgent decompressive intervention is required for patients with sepsis and obstructing stones. ${ }^{2}$ However, there is no clear recommendation about the optimal time to treat non-urgent obstructing stones. $^{2}$

Thus, urologists must decide which cases can be safely delayed. To support such prioritization of cases, most experts recommend that non-complicated kidney stones be postponed. ${ }^{3}$ In order to support decision-making when delaying care for kidney stones and to better understand the impact of delaying kidney stone surgery, we aimed to perform a systematic review of the outcomes of early elective versus delayed elective intervention for acute episodes of renal colic with obstructing stones. 


\section{Methods}

We conducted a systematic review of the literature.

\section{Search strategy}

We searched MEDLINE and EMBASE for all articles, regardless of year of publication. The search strategy was built by an experienced librarian and designed to include subject headings (MeSH/Emtree), including "kidney calculi" or "nephrolithiasis" AND "time to treatment". Search filters for the following key phrases were added: "kidney stone", "lithiasis", "ureteric stone", "time factors", "(time OR delay) to (treatment OR intervention OR lithotripsy OR surgery)". We limited our search to human studies written in English or French.

\section{Inclusion and exclusion criteria}

Studies available as a full-text or conference proceeding were included without restrictions on modality. Studies evaluating the outcomes of early elective versus delayed elective cases for acute episodes of renal colic with obstructing stones were eligible for inclusion. We defined elective cases as an episode of renal colic without fever, renal insufficiency and/or unrelenting pain. Commentaries and studies focusing on asymptomatic non-obstructing stones, pediatric and pregnant populations were excluded.

\section{Review strategy}

Duplicates were removed. Titles and abstracts were reviewed by two independent investigators (A.A. \& I.S.) and discrepancies were resolved by a third author (D.D.N.). Articles retained for full-text review were also independently reviewed by three independent investigators (A.A., N.B. \& D.D.N.). Discrepancies were resolved by consensus.

\section{Study synthesis}

Studies were qualitatively synthesized. We abstracted the following information: year of publication, study design, number and characteristics of participants including stage of disease and method of diagnosis, inclusion and exclusion criteria, intervention and outcome measures. Outcomes measures were not determined a priori considering the scarcity of previous literature on the topic.

\section{Results}

We retained 22 studies for full-text review selected from 675 initially identified records. Fifteen of the studies were excluded as they did not meet inclusion or exclusion criteria. The 7 retained studies provided relevant information regarding our clinical question, however none of them specifically evaluated the impact of delayed surgery on long-term outcomes. A broad range of study designs were left with an important heterogeneity 
regarding the population of interest, clinical presentation and management. The PRISMA flow chart is presented in Figure 1.

Among the selected studies, three groups assessed the outcomes associated with longer delays to surgery. They reported that important delays to definitive surgical management led to repeated emergency department (ED) visits, more medical imaging exams, readmissions and increased morbidity (eg. surgical decompression, postoperative complications). ${ }^{1,4,5}$ Kirshenbaum et al. found an increased rate of sepsis during the postoperative period in patients who underwent ureteral stent prior to surgery $(0.84 \%)$ compared to those who underwent upfront URS $(0.47 \%)(\mathrm{p}<0.001)$. Risk of renal insufficiency, pyelonephritis or ureteral strictures was not associated with longer delays. Bajaj et al. noted that it may be safe to delay surgery in patients with symptoms for $<3$ days, no history of stone disease, a low stone burden and an absence of abdominally located stones. ${ }^{6}$

The effectiveness and safety of early (within 12-72h) extracorporeal shock wave lithotripsy (eESWL) was documented in three studies. ${ }^{7-9}$ The stone-free rate (SFR) was higher in the eESWL (SFR=52.8-73.2\%) groups compared to the delayed ESWL (dESWL) groups $(\mathrm{SFR}=11.8-40.0 \%)$. Bucci et al. reported a reduced number of additional interventions $(13.9 \%$ vs $44.1 \%, \mathrm{p}=0.039)$ and duration of hospitalisation $(1.36$ days vs 2.21 days, $p=0.046$ ) in patients who underwent eESWL as compared to dESWL. 7 The complication rate was similar between early and delayed ESWL groups (respectively, $8.3 \%$ vs $5.9 \%, p=0.691)^{7}$

\section{Discussion}

As elective procedures slowly restart with the COVID-19 pandemic seemingly relenting momentarily, knowing which cases to prioritize and understanding the impact of delayed treatment becomes primordial. As such, we conducted a systematic review to examine the impact of delays on acute (but non emergent cases) stone events. We found that studies on this topic are lacking -- as such current guidelines on kidney stones should primarily be guided by expert opinion.

With longer waiting lists, urologists might have to face more complicated cases. ${ }^{3}$ In a retrospective study, Gul et al. demonstrated that the rate of complicated kidney stone disease increased significantly during the COVID-19 period. ${ }^{10}$ This could be explained by fear of infection leading patients to delay medical consultation, as well as non-optimal follow-up subsequent to discharge from the ED. Therefore, patients should have prompt access to urologic care and be closely evaluated after discharge in order to identify and prevent complications. Hiller et al. supported telehealth as an appropriate tool to promote patient education, patient's involvement regarding treatment decisions, and to identify the need for ESWL and emergent URS. ${ }^{11}$ 
Medical associations and research groups have tried to establish guidelines and recommendations to follow during the COVID-19 pandemic. The European Association of Urology (EAU) recommends an interventional treatment (ESWL, URS or decompression) within $<6$ weeks for obstructing ureteral stones that are considered not suitable for medical expulsive therapy (MET). ${ }^{12}$ Similarly, Socarrás et al. recommend interventional treatment within 2-4 weeks for non-complicated obstructive ureteral stone $>8-10 \mathrm{~mm} .{ }^{13}$ Socarrás et al. and Carneiro et al. also endorse the use of URS when a surgical procedure is indicated in order to reduce the need of additional interventions. ${ }^{13,14}$ This is consistent with our finding that upfront URS appeared to prevent subsequent interventions, readmissions and complications associated with the placement of a temporary ureteral stent. ${ }^{5}$ Furthermore, eESWL may be another interesting approach as it is safe, noninvasive and doesn't require anesthesia.

Patients who underwent ureteral stent insertion during the COVID-19 pandemic should be closely monitored while waiting for definitive surgery. ${ }^{1,4,5}$ Indeed, we found ureteral stents conferred a higher risk of readmission while awaiting definitive surgery. ${ }^{1,5}$ These patients may experience stent related side-effects (eg. urgency, hematuria, pain) and are at a higher risk of complications such as ureteral stent infection and calcification, pyelonephritis and urosepsis. In a systematic review of published recommendations during the COVID-19 pandemic, Heldwein et al. reported that patients with pre-existing stents should be prioritized. With no clear consensus, the acceptable delay before stent removal was between $6-12$ weeks. ${ }^{15}$

Based on our findings, we recommend that patients with non-complicated obstructive stones should be treated within 6 weeks to avoid repeated ED visits, more medical imaging exams, readmissions and increased morbidity. When early interventions (upfront-URS or eESWL) are not possible, patients should be closely monitored after hospital discharge. When an interventional treatment is still indicated, URS should be preferred over ureteral stent drainage.

This study has limitations. First, the number of studies included was low as a result of the limited data available. Additionally, none of the studies directly evaluated the effect of delayed treatment on outcomes. Lastly, there was significant heterogeneity regarding the design, sample size, and quality of the selected studies. Many studies were limited by potential confounding factors. Despite its limitations, our review identifies the need for expert recommendations regarding kidney stones treatment delay.

\section{Conclusions}

There is a paucity of data on the impact of delayed treatment in patients with acute episodes of renal colic with obstructing stones. However, the literature review reveals 
that patients who experience delays to definitive surgery are more prone to have repeated ED visits, repeated imaging and upper urinary tract decompression. We found that upfront-URS and eESWL are safe procedures with clinical advantages. Data indicating long term kidney damage in patients with delayed surgical intervention was not reported. Further studies are required in order to develop a safe and efficient prioritization approach to kidney stones surgery.

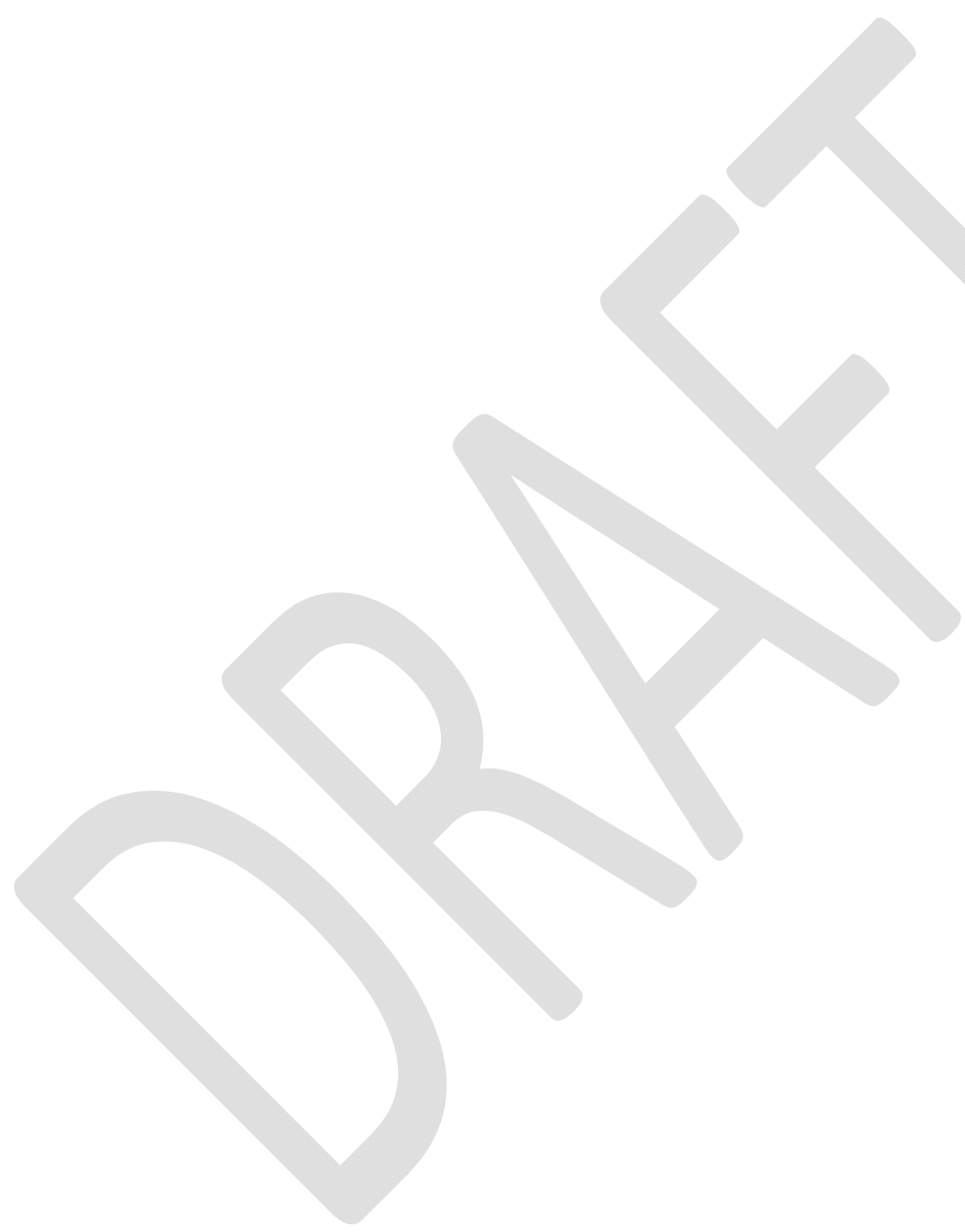




\section{References}

1. Smith T, Gruber M, Simoes A, Krishnan R, Shrotri N. Should a 31/62-day target be applicable to urinary stone patients with indwelling stents? Journal of Clinical Urology. 2015;8(1):38-41.

2. Türk C, Neisius A, Petŕík A, et al. EAU guidelines on urolithiasis. European Association of Urology guidelines. Published online 2018.

3. Proietti S, Gaboardi F, Giusti G. Endourological Stone Management in the Era of the COVID-19. Eur Urol. 2020;78(2):131-133.

4. Brubaker WD, Dallas KB, Elliott CS, et al. Payer Type, Race/Ethnicity, and the Timing of Surgical Management of Urinary Stone Disease. J Endourol. 2019;33(2):152-158.

5. Kirshenbaum EJ, Doshi C, Dornbier R, et al. Socioeconomic Disparities in the Acute Management of Stone Disease in the United States. J Endourol. 2019;33(2):167-172.

6. Bajaj M, Yuan L, Holmes LC, Rice M, Zargar-Shoshtari K. Predictors of surgical intervention following initial surveillance for acute ureteric colic. World J Urol. 2018;36(9):1477-1483.

7. Bucci S, Umari P, Rizzo M, et al. Emergency extracorporeal shockwave lithotripsy as opposed to delayed shockwave lithotripsy for the treatment of acute renal colic due to obstructive ureteral stone: a prospective randomized trial. Minerva Urol Nefrol. 2018;70(5):526-533.

8. Panah A, Patel S, Bourdoumis A, Kachrilas S, Buchholz N, Masood J. Factors predicting success of emergency extracorporeal shockwave lithotripsy (eESWL) in ureteric calculi--a single centre experience from the United Kingdom (UK). Urolithiasis. 2013;41(5):437-441.

9. Uguz S, Senkul T, Soydan H, et al. Immediate or delayed SWL in ureteric stones: a prospective and randomized study. Urol Res. 2012;40(6):739-744.

10. Gul M, Kaynar M, Yildiz M, et al. The Increased Risk of Complicated Ureteral Stones in the Era of COVID-19 Pandemic. J Endourol. 2020;34(8):882-886.

11. Hiller SC, Dauw CA, Ghani KR. Kidney Stone Care and the COVID-19 Pandemic: Challenges and Opportunities. J Urol. Published online July 27, 2020:101097JU0000000000001303.

12. EAU Guidelines Office Rapid Reaction Group. Recommendations from the EAU Urolithiasis Guidelines Panel applicable during the COVID-19 pandemic, 2020. https:// uroweb.org/wp-content/uploads/Combined-non-oncologyCOVID-recommendations.pdf Accessed July 29, 2020.

13. Socarrás MER, Esperto F, Bapstistussi MD, et al. Endourology (Lithiasis). Management, surgical considerations and follow-up of patients in the COVID19 era. Int Braz J Urol. 2020;46(suppl.1):39-49.

14. Carneiro A, Wroclawski ML, Nahar B, Soares A. Impact of the COVID-19 Pandemic on the Urologist's clinical practice in Brazil: a management guideline proposal for low-and middle-income countries during the crisis period. Int Braz J Urol. 2020;46: 501-510. 
15. Heldwein FL, Loeb S, Wroclawski ML, et al. A Systematic Review on Guidelines and Recommendations for Urology Standard of Care During the COVID-19 Pandemic. European Urology Focus. 2020;6(5):1070-1085. 
Figures and Tables

Fig. 1. PRISMA diagram.

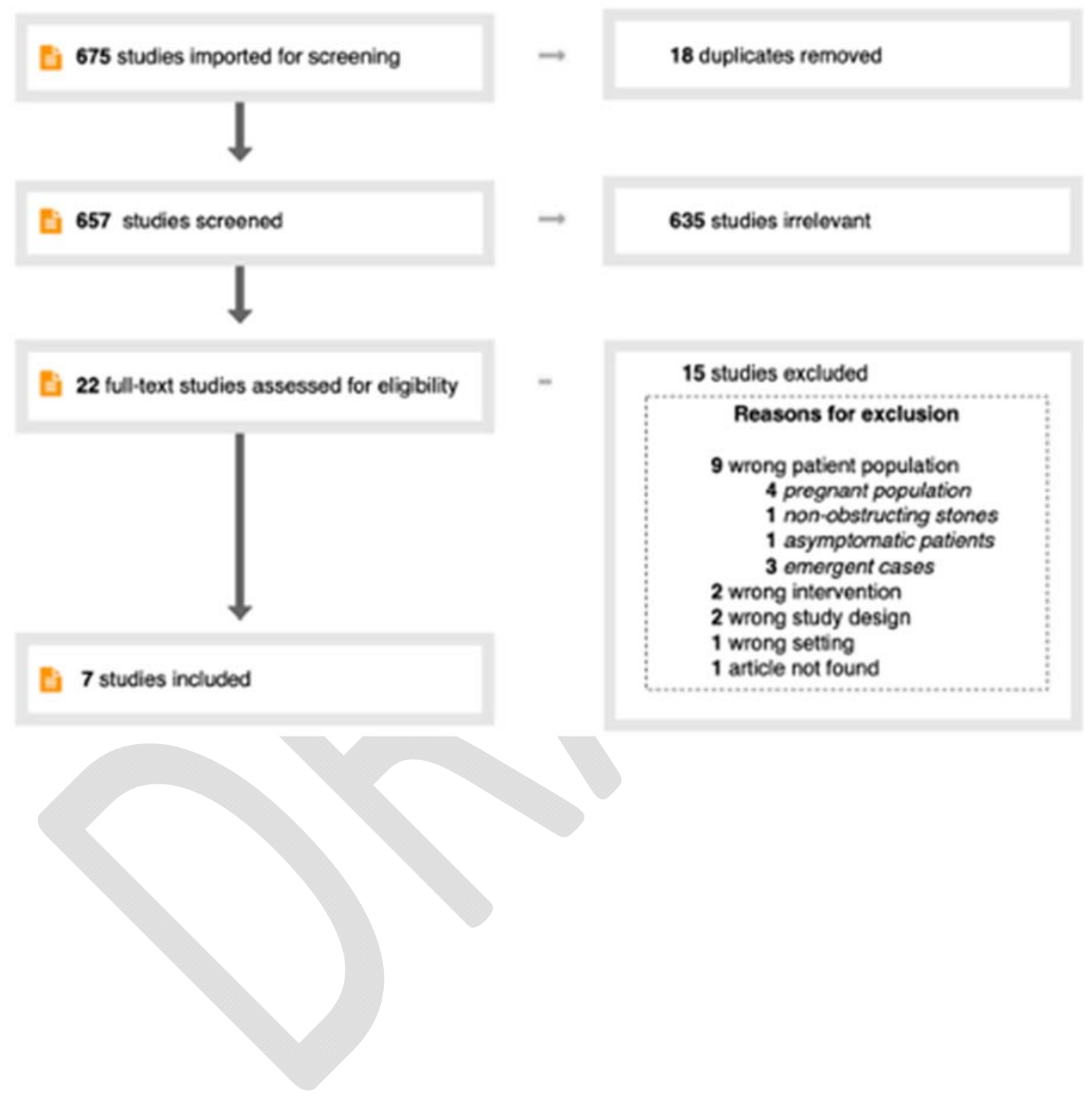




\begin{tabular}{|c|c|c|c|c|c|c|}
\hline Table 1. Study characteristics & Aims & Sample & Results & Key findings \\
\hline Authors & Year & $\begin{array}{c}\text { Type of } \\
\text { study }\end{array}$ & Brubacker et \\
al ${ }^{4}$
\end{tabular}




\begin{tabular}{|c|c|c|c|c|c|c|}
\hline & & & $\begin{array}{c}\text { with a primary } \\
\text { diagnosis of } \\
\text { urolithiasis }\end{array}$ & & $\begin{array}{c}\text { Readmission rate within } 30 \\
\text { days: } \\
\text { Upfront URS: } 5.89 \% \\
\text { Stent alone: } 8.21 \% \\
\mathbf{p}<\mathbf{0 . 0 0 1} \\
\text { Stone procedures within } 90 \\
\text { days: } \\
\text { Upfront URS: } 10.0 \% \\
\text { Stent alone: } 49.25 \% \\
\text { p }<\mathbf{0 . 0 0 1} \\
\text { Postoperative sepsis: } \\
\text { Upfront URS: } 0.47 \% \\
\text { Stent alone: } 0.84 \% \\
\mathbf{p}<\mathbf{0 . 0 0 1} \%\end{array}$ & $\begin{array}{l}\text { postoperative } \\
\text { complications. }\end{array}$ \\
\hline${\text { Bajaj et } \mathrm{al}^{6}}^{6}$ & 2018 & $\begin{array}{l}\text { Retrospective } \\
\text { cohort study }\end{array}$ & $\begin{array}{l}\text { Identified stone- } \\
\text { related factors } \\
\text { predicting the } \\
\text { need for surgical } \\
\text { intervention in } \\
\text { patients } \\
\text { presenting acute } \\
\text { ureteric colic who } \\
\text { were not } \\
\text { considered } \\
\text { surgical } \\
\text { candidates }\end{array}$ & $\mathrm{n}=527$ & $\begin{array}{c}\text { Predictors of need for surgery: } \\
\text { Length of symptoms }>3 \text { days } \\
\text { Previous history of stone } \\
\text { disease } \\
\text { Absence of alpha-blocker } \\
\text { therapy } \\
\text { Stone burden } \\
\text { Abdominal location of stone }\end{array}$ & $\begin{array}{l}\text { When conservative } \\
\text { approach was selected, } \\
\text { patients presenting with } \\
\text { symptoms }>3 \text { days, } \\
\text { history of stones disease, } \\
\text { important stone burden, } \\
\text { and/or abdominal stone } \\
\text { location were more likely } \\
\text { to require surgical } \\
\text { intervention after } \\
\text { discharge. }\end{array}$ \\
\hline
\end{tabular}




\begin{tabular}{|c|c|c|c|c|c|c|}
\hline Bucci et al ${ }^{7}$ & 2018 & $\begin{array}{l}\text { Randomized } \\
\text { clinical trial }\end{array}$ & $\begin{array}{l}\text { Evaluate the } \\
\text { efficacy of early } \\
\text { ESWL as first- } \\
\text { line treatment in } \\
\text { patients with } \\
\text { obstructive } \\
\text { ureteral stone }\end{array}$ & $\mathrm{n}=74$ & $\begin{array}{c}\text { Hospitalization time: } \\
\text { Early ESWL: } 1.36 \text { days } \\
\text { Delayed ESWL: } 2.21 \text { days } \\
\text { p=0.046 } \\
\text { Stone-free rate at } 24 \text { hours: } \\
\text { Early ESWL: } 52.8 \% \\
\text { Delayed ESWL: } 11.8 \% \\
\text { p }<0.001 \\
\text { URS intervention: } \\
\text { Early ESWL: } 13.9 \% \\
\text { Delayed ESWL: } 44.1 \% \\
\text { p=0.039 } \\
\text { Complication rate: } \\
\text { Early ESWL: } 8.3 \% \\
\text { Delayed ESWL: } 5.9 \% \\
\text { p=0.691 }\end{array}$ & $\begin{array}{c}\text { Early ESWL and } \\
\text { deferred ESWL are both } \\
\text { safe procedures for first- } \\
\text { line treatment of } \\
\text { obstructive ureteral } \\
\text { stones. } \\
\text { Early ESWL } \\
\text { demonstrated a higher } \\
\text { stone-free rate and } \\
\text { reduced the number of } \\
\text { additional interventions } \\
\text { and the duration of } \\
\text { hospitalization. }\end{array}$ \\
\hline
\end{tabular}


Assad et al

Impact of surgery delay on stone outcomes

\begin{tabular}{|c|c|c|c|c|c|c|}
\hline Smith et $\mathrm{al}^{1}$ & 2015 & $\begin{array}{l}\text { Retrospective } \\
\text { study }\end{array}$ & $\begin{array}{l}\text { Evaluate the } \\
\text { readmission rate } \\
\text { for patients with } \\
\text { ureteral stents } \\
\text { awaiting surgery }\end{array}$ & $\mathrm{n}=378$ & 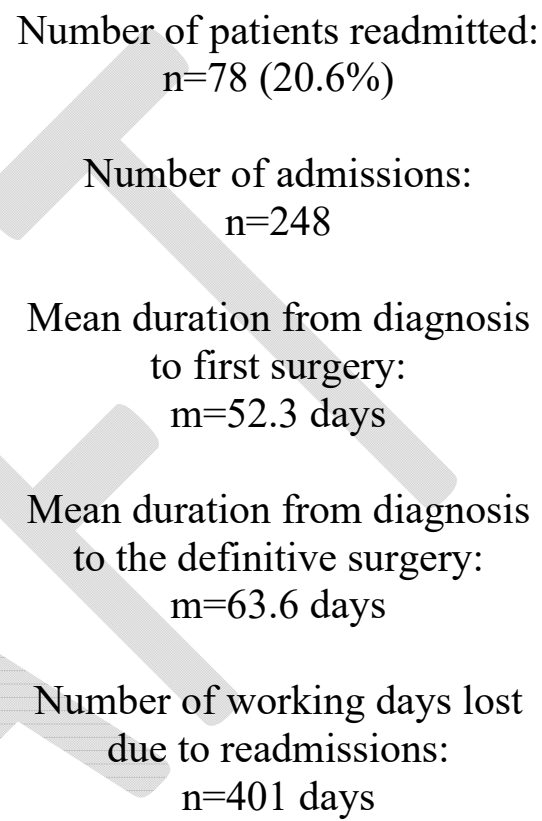 & $\begin{array}{l}\text { Patients with ureteral } \\
\text { stents are at risk of } \\
\text { complication during the } \\
\text { waiting period until } \\
\text { definitive surgery. } \\
\\
\text { Patients with urolithiasis } \\
\text { often belong to the } \\
\text { working age population } \\
\text { (18-65 years old), which } \\
\text { results in loss of income } \\
\text { and significant economic } \\
\text { impact. }\end{array}$ \\
\hline
\end{tabular}




\begin{tabular}{|c|c|c|c|c|c|c|}
\hline Panah et $\mathrm{al}^{8}$ & 2013 & $\begin{array}{c}\text { Case series } \\
\text { study }\end{array}$ & $\begin{array}{l}\text { Evaluated the } \\
\text { factors } \\
\text { influencing the } \\
\text { outcome of } \\
\text { emergency } \\
\text { ESWL (within } 72 \\
\text { hours of } \\
\text { presentation) in } \\
\text { patients } \\
\text { presenting with a } \\
\text { first episode of } \\
\text { ureteric colic }\end{array}$ & $\mathrm{n}=97$ & $\begin{array}{c}\text { Stones characteristics: } \\
\text { Stone mean size: } 6.73 \mathrm{~mm} \\
\text { Stone size range: } 3-12 \mathrm{~mm} \\
\text { Stone density range: } 286-837 \\
\text { HU } \\
\text { Outcomes after eESWL: } \\
\text { Stone-free rate: } 73.2 \% \\
\text { ESWL done within } 24 \text { hours: } \\
\text { Stone-free group: } 77.5 \% \\
\text { Non-stone-free group: } 62 \% \\
\text { p=n/a } \\
\text { Major complications: } \\
\text { None }\end{array}$ & $\begin{array}{l}\text { Emergency ESWL is a } \\
\text { safe and effective } \\
\text { treatment in selected } \\
\text { patients presenting a first } \\
\text { episode of renal colic. } \\
\text { The intervention success } \\
\text { rate was higher in } \\
\text { patients who received } \\
\text { ESWL within } 24 \text { hours. }\end{array}$ \\
\hline 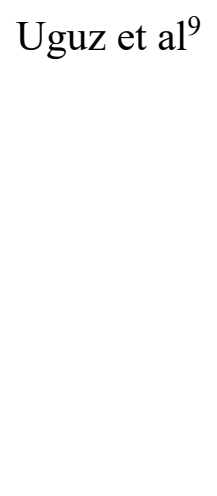 & 2012 & $\begin{array}{l}\text { Randomized } \\
\text { clinical trial }\end{array}$ & $\begin{array}{l}\text { Evaluate the } \\
\text { efficacy and } \\
\text { outcomes of } \\
\text { immediate ESWL } \\
\text { compared to } \\
\text { delayed ESWL in } \\
\text { management of } \\
\text { ureteric stones }\end{array}$ & & $\begin{array}{c}\text { Stone-free rate: } \\
\text { Early ESWL: } 53.1 \% \\
\text { Delayed ESWL: } 40.0 \% \\
\text { p=0.353 } \\
\\
\text { Mean time from diagnosis to } \\
\text { stone clearance } \\
\text { Immediate ESWL: } 6.31 \text { days } \\
\text { Delayed ESWL: } 9.82 \text { days } \\
\mathbf{p}=\mathbf{0 . 0 3 3}\end{array}$ & $\begin{array}{l}\text { Immediate ESWL is a } \\
\text { safe procedure and } \\
\text { appears to shorten the } \\
\text { time from diagnosis to } \\
\text { stone clearance compared } \\
\text { to delayed ESWL. }\end{array}$ \\
\hline
\end{tabular}


Assad et al

Impact of surgery delay on stone outcomes

\begin{tabular}{|c|c|c|c|c|c|}
\hline & & & & URS intervention: \\
& & & & $\begin{array}{c}\text { Immediate ESWL: } 6.2 \% \\
\text { Delayed ESWL: } 19.4 \%\end{array}$ & \\
& & & & p=0.472 & \\
\hline
\end{tabular}

CT: computed tomography; ED: emergency department; ESWL: electric shockwave lithotripsy; PCNL: percutaneous nephrolithotomy; URS: ureteroscopy. 